\section{Autocensure de la protéine EBNA1 pour échapper à la reconnaissance immunitaire}

Bénédicte Manoury, Robin Fåhraeus

\author{
B. Manoury: Institut Curie, \\ Inserm U.520, \\ 12, rue Lhomond, \\ 75005 Paris, France. \\ R. Fåhraeus: Laboratoire \\ de Pharmacologie, \\ Hôpital Saint-Louis, EPI 334, \\ 1 , avenue Claude Vellefaux, \\ 75010 Paris, France. \\ b.manoury@dundee.ac.uk
}

> Les molécules du complexe majeur d'histocompatibilité de classe I (CMHl) sont responsables de la présentation d'antigènes endogènes (par exemple viraux ou bactériens) aux lymphocytes $\mathrm{T}$ (LT) $\mathrm{CD}^{+}$et sont donc indispensables à la mise en place de la réponse immunitaire spécifique. Pratiquement, tous les types cellulaires chez les vertébrés sont capables de présenter ces peptides endogènes. Dans un processus appelé «tolérance», les LT reconnaissant les molécules du CMH I associées à des peptides du soi sont éliminés prévenant ainsi le développement de maladies auto-immunes. Au contraire, à la suite d'une infection virale, les molécules du CMH-I nouvellement synthétisées transportent les peptides viraux jusqu'à la surface des cellules infectées et sont ensuite reconnues par des LT spécifiques de ces complexes CMH I-peptides. Les LT, alors activés, produisent un cocktail d'effecteurs immuns permettant ainsi d'interférer avec la réplication virale, soit directement en tuant la cellule infectée, soit plus subtilement en reprogrammant la cellule infectée par le virus, défavorisant ainsi la réplication virale. Une des caractéristiques des LT est leur remarquable sensibilité. Face à un adversaire aussi malin, la plupart des virus adoptent une stratégie de «frappe et court» en se déplaçant de cellules hôtes en cellules hôtes avec une telle rapidité qu'ils n'ont pas le temps d'af- fronter les LT. Au contraire, les LT ont besoin de temps pour se diviser afin de réagir face au nombre croissant de cellules infectées. De nombreux exemples ont montré que certains virus interfèrent avec la voie de présentation des molécules du CMH-I, soit en interagissant avec le protéasome (complexe chargé de dégrader les protéines au sein de la cellule) bloquant ainsi la production de peptides, soit en inhibant le transport de peptides par les molécules TAP (transporter associated proteins, molécules transportant les peptides du cytosol vers le réticulum endoplasmique) ou encore en bloquant le chargement des peptides sur la molécule du $\mathrm{CMH}$ I dans le réticulum endoplasmique [1].

Le virus d'Epstein-Barr ( $\varepsilon B V)$ a, lui, choisi une stratégie différente. Ce virus infecte les individus à vie et est exprimé dans certains types de cellules cancéreuses comme le lymphome de Burkitt [2]. Pour pérenniser sa réplication virale, $\varepsilon B V$ doit exprimer une de ses protéines: EBNAl (Epstein-Barr virus nuclear antigen 1 ) qui, dans sa région amino-terminale, est composée d'une répétition d'acides aminés tels que glycine et alanine (GAR, glycine alanine repeat). Cette séquence a été proposée comme étant responsable de l'inhibition de sa propre dégradation par le protéasome [3]. En effet, la plupart des peptides viraux présentés par les molécules du CMH I des cellules infectées provien- nent de la dégradation par le protéasome. En bloquant ainsi la production de peptides spécifiques de la protéine EBNAl, la région GAR empêche donc la présentation de ces peptides endogènes aux LT CD8 ${ }^{+}$. Cependant, si ce seul mécanisme expliquait l'absence de réponse $T$, les cellules infectées par EBV devraient exprimer d'énormes quantités de protéine EBNAl puisque celle-ci n'est plus protéolysée. Or, ce n'est pas le cas, car il est très difficile de détecter cette protéine EBNAl dans les cellules infectées. De plus, une réponse $T$ cytotoxique peut être induite contre des peptides d'EBNAl par un mécanisme appelé cross presentation [4]. Ces cellules T peuvent reconnaître des molécules du CMH I chargées en peptides exogènes provenant de la protéine EBNAl mais pas des molécules du CMH I présentant des peptides endogènes.

Dans un travail récent, nous montrons que l'inhibition du protéasome n'est pas suffisante pour bloquer la présentation d'EBNAl aux LT. En fait, le virus a choisi une autre stratégie, celle qui consiste à bloquer sa propre synthèse d'EBNAl, ce qui explique pourquoi la protéine $\varepsilon B N A l$ est peu exprimée dans la cellule infectée [5].

Pourquoi le virus a-t-il opté pour cette stratégie de réduction de l'expression cellulaire d'દBNAl? La question est encore sans réponse. Une possibilité est qu'en inhibant ainsi sa propre traduction, EBV réduit sa production de pep- 
tides via les DRiP (defective ribosomal products). Les DRiP sont les produits «imparfaits» issus de la machinerie de traduction. Ils constituent à peu près un tiers des protéines nouvellement synthétisées qui sont très rapidement dégradées (environ 30 minutes) après leur synthèse. Les différentes formes de DRiP incluent les protéines «mal formées» mais proprement traduites ainsi que les polypeptides résultant des erreurs de fidélité de la machinerie de transcription et de traduction. Beaucoup d'arguments convergent pour faire des DRiP la principale source de peptides associés aux molécules du CMH I $[6,7]$. Dans ce travail, nous avons montré que c'est probablement l'initiation de la traduction de la protéine EBNAl qui est inhibée. C'est la séquence GAR qui est directement responsable de cette inhibition. De cette façon, le virus est certain de ne produire aucun peptide pouvant constituer des DriP (Figure 1). En effet, si cette séquence GAR est déplacée du côté carboxy-terminal de la protéine EBNAl, elle est alors trop éloignée du site d'initiation, et elle ne bloque plus complètement la traduction d'eBNAl. Par conséquent des peptides peuvent être produits via les DRiP et induire une réponse cytotoxique [5]. Un autre récent travail dirigé par l'équipe de Nilab Shastri [8] vient de montrer également que certains peptides endogènes viraux, qui induisent une réponse $T$ cytotoxique, peuvent être produits d'une façon qui n'a rien de conventionnel à partir de gènes codant pour la région 3 ' non traduite. De plus, la traduction de l'ARNm peut démarrer au niveau d'un codon CUG, codon très différent du codon utilisé dans le cadre normal de lecture. En conclusion, comme le montrent ces deux travaux, ce qui est important pour le virus afin d'éviter une reconnaissance $T$, c'est d'agir non seulement au niveau protéique mais aussi au niveau de son ARNm. $\diamond$

Inhibition of synthesis and antigen presentation by protein EBNA 1

\section{RÉFÉRENCES}

1. Yewdell JW, Hill AB. Viral interference with antigen presentation. Nat Immunol 2002; 3: 1019-25.

2. Chen F, Zou JZ, di Renzo L, et al. A subpopulation of latently infected normal Bcells resemble Burkitt lymphoma (BL) cell lines in expressing EBNAl but not EBNA2 or LMP1. J Virol 1995; 69: 3752-8.

3. Levitskaya J, Coram M, Levitsky $V$, et al. Inhibition of antigen processing by the internal repeat region of the Epstein-Barr virus nuclear antigen-1. Nature 1995 ; 375 : 685-8.
4. Blake N, Haigh T, Shaka'a $G$, et al. The importance of exogenous antigen in priming the human $C D 8+T$ cell response: Lesson from the EBV nuclear antigen EBNAl. J Immunol 2000; 165: 7078-87.

5. Yin Y, Manoury B, Fahraeus R. Self-inhibition of synthesis and antigen presentation by EpsteinBarr virus-encoded EBNAl. Science 2003; 301: 1371-4

6. Princiotta MF, Finzi D, Pian $\mathrm{SB}$, et al. Quantitating protein synthesis, degradation and endogenous antigen processing. Immunity 2003; 18: 343-54.
7. Yewdell JW, Anton LC, Bennink JR. Defective Ribosomal Products (DRiPs). A major source of antigenic peptides for MHC Class I molecules? J Immunol 1996; 157: 1823-6.

8. Schwab SR, Li KC, Kang C, et al. Constitutive display of cryptic translation products by MHC class I molecules. Science 2003; 301: 1367-71.

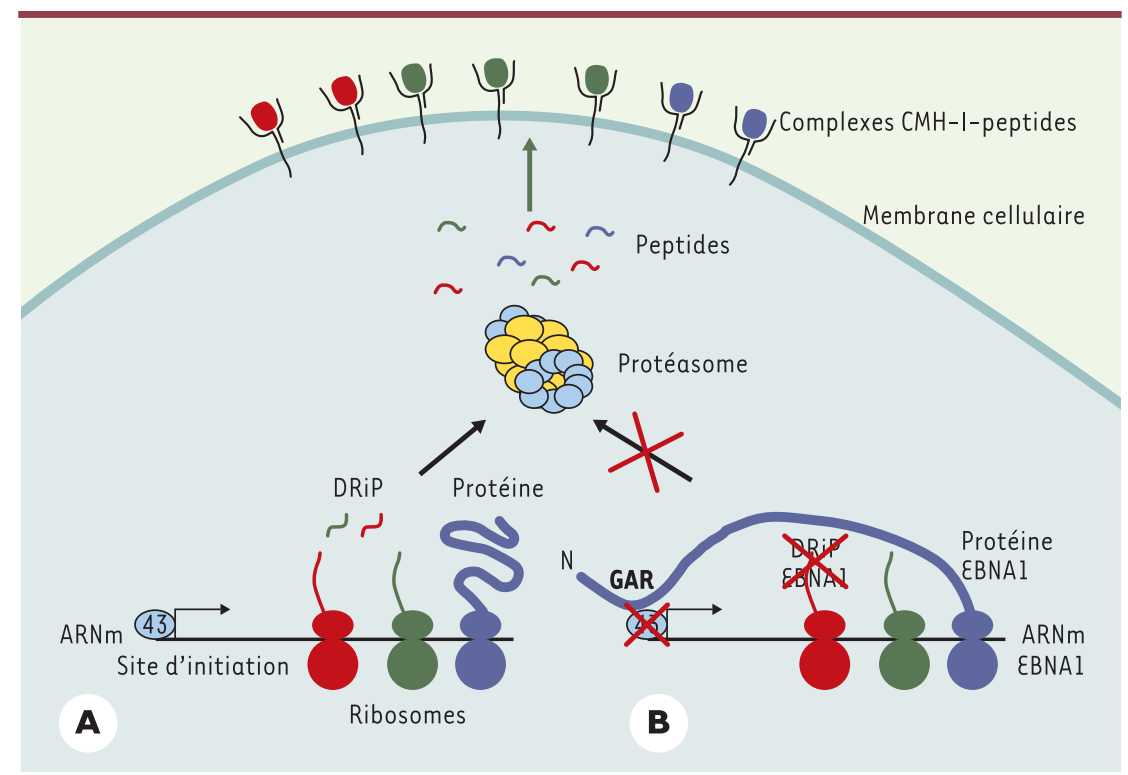

Figure 1. Production de peptides dérivant de la protéine EBNA1. A. Les ribosomes traduisent l'information génétique à partir d'ARNm (les trois couleurs correspondent aux différentes phases de lecture). La source majeure de peptides endogènes provient des DRiP (defective ribosomal products). Les DRiP sont la conséquence des imperfections de la machinerie de traduction. Les différentes formes de DRiP incluent les protéines «mal formées» mais proprement traduites et les polypeptides résultant des erreurs de fidelité de la machinerie de transcription et de traduction. Les DRiP sont ensuite dégradés par le protéasome afin de produire les peptides s'associant aux molécules du CMH I. Ces complexes CMH I-peptides sont alors transportés jusqu'à la surface cellulaire où ils induisent une stimulationT. B. Dans le cas d'€BV, la protéine દBNAl contient une séquence appelée GAR localisée dans sa partie amino-terminale qui inhibe sa propre synthèse protéique en bloquant l'initiation de la traduction. De cette façon, la région GAR s'assure qu'aucun peptide ne peut être produit par les DRiP. II en résulte l'absence de réponse T cytotoxique contre la protéine EBNAl. 